\title{
A Two-step Numerical Method for Efficient Analysis of Structural Response to Blast Load
}

\author{
J. Li, H. Hao* \\ School of Civil and Resource Engineering, the University of Western \\ Australia, 35 Stirling Highway, Crawley, WA 6009, Australia \\ Received on 3 Dec 2010, Accepted on 15 Jan 2011
}

\begin{abstract}
Even with modern computer power, detailed numerical modeling and simulation of structure response to blast loads are still extremely expensive and sometimes prohibitive because it is very time consuming and requires huge computer memory. Often compromise has to be made between simulation efficiency and simulation accuracy. A lot of research efforts have been spent on improving the computational efficiency. Most of these researches concentrate on simplifying the structures, such as simplifying a structure to an equivalent SDOF system, use smeared reinforcement steel and concrete model, use substructure approach to only model part of the structure in detail. Although these approaches under certain conditions yield reliable predictions, each of them has its associated limitations. Recently a two-step method was developed to improve the computation and modeling efficiency of structure response to blast loads. Instead of simplifying the structure, the proposed method calculates the structural responses in two steps. The first step calculates the structural responses in the loading phase and the second calculates the free vibration responses with the velocity profile of the structure at the end of the loading phase as initial conditions. Using a reinforced concrete beam as the example, it was found that the proposed method yields reliable predictions of the overall beam deflection and stress in longitudinal reinforcement bars with less than $10 \%$ computational time as compared to a detailed FE model simulation. However, the predicted stress in hoop reinforcements near the beam supports is not as good. In this paper, the method is improved by also including displacement response at the end of the forced-vibration phase as the initial conditions in the free vibration analysis. The same reinforced concrete beam is used. The results show that including the displacement initial conditions in the two-step method leads to an improved prediction of the beam responses. Parametric calculations are performed in this
\end{abstract}

${ }^{*}$ Corresponding author. E-mail addres: hao@civil.uwa.edu.au 
study by varying the blast loading amplitude and duration. Using the detailed FE model simulation results as benchmark, the prediction errors on various response quantities and savings on computational times of the proposed two-step method with respect to different blast loading scenarios are presented. The accuracy and efficiency of the proposed method in predicting structural responses and damage to blast loadings are demonstrated in this paper.

\section{INTRODUCTION}

Significant efforts have been spent on studying the structural responses to blast loadings. Historically the research was mainly focused on the dynamic response and durability of military facilities. Nowadays due to the increased threats from terrorist activities, more attention has been given to the performance of civilian structures under blast loading conditions. The methodologies available nowadays can be mainly classified into three categories: experimental, theoretical and numerical. Experimental studies [1-4], no matter they are full-scale structures, scaled model structures or structural components, can provide a wealth of useful data. But the experimental tests are always expensive and often prohibitive owing to safety and environmental consideration. Theoretical studies which are usually based on idealized models such as the Mindlin elastic plate theory [5], and Timoshenko beam model [6-8], can provide valuable information for locating the damage and establishing damage criteria for structural components. But the theoretical analyses often could not capture the complex blast loading and structural conditions in a real situation. With the development of computer technology, numerical simulations have been becoming more and more popular in modelling structural responses to blast loads. Using existing computer codes with proper material models it is possible to carry out a 3-dimensional reproduction of the $\mathrm{RC}$ structures subjected to realistic explosive loadings.

Many successful numerical simulations of blast wave propagation, blast wave structure interaction, and structure responses to blast loads have been reported. Shi et al. [9] conducted detailed modelling and simulations of blast wave and RC column interaction by using commercial software AUTODYN [10], and it was found that the column dimension and geometry have significant influence on blast wave propagation, hence on the blast loads acting on columns. Using numerical simulation results obtained with commercial code LSDYNA [11], Shi et al. [12] derived analytical formulae to derive pressure-impulse curves of RC columns. Xu and Lu [13] developed a 3D concrete plate model in LS-DYNA to study its spalling process under explosive loads, and the numerical results show favourable agreement with the existing experiment data. Luccioni et al. [14] used the hydrocode AUTODYN to simulate responses of a highrise building subjected to blast loads induced by a $400 \mathrm{~kg}$ TNT explosion. All the process from detonation to the complete demolition, including the propagation of the blast wave and its interaction with the structure was well reproduced. Hao et al. [15] conducted numerical simulations of progressive collapse of a RC frame structure under blast loads in LS-DYNA. Shi et al. [16] presented an improved method of numerical simulations of blast-induced RC structure progressive collapse by introducing the non-zero initial conditions and damage of the structure caused by direct blast loads. Numerical method is also used to simulate bridge responses and collapse to blast loads under different explosion scenarios [17, 18]. Recently Riedel et al. [19] also presented a discussion on the various engineering (usually based on SDOF model) and numerical tools (Hydrocode) for analysis of RC structure responses to blast loads. 
Despite of more and more numerical simulations of structural responses to blast loads have been reported in the literature, application of detail numerical simulation in practice is still limited. This is because modelling the extremely short duration blast loading and large blast loading amplitude requires very small element sizes to convert the blast energy into the structure in numerical simulations. As a result, it usually results in huge FE models and long computer hours in numerical simulation of structure response to blast loads. When it comes to the analysis of the whole structure response to blast loads, it is often impossible to conduct the conventional Finite Element analysis of the structure in practice due to the limited computational resource and time.

Because of the computational cost is often beyond the affordability in design and analysis of structural responses to blast loads, in practice, the structure is often simplified into a SDOF system for analysis. Krauthammer [20] simplified a reinforced concrete slab to an equivalent SDOF system and analyzed its response and failure to blast loads. In that study, two failure criteria to determine the behaviour of the reinforced concrete slab were used. The study found that the method did predict the type of failure with reasonable accuracy, however it was noted that the method could not replace more advanced techniques of prediction of structural response. For reinforced concrete beams and one-way slabs under the blast loading condition, Krauthammer et al. [21] developed a step-by-step analytical method based on the SDOF model and considered the material nonlinearities in the structure dynamic analysis. Yang and Lok [22] developed a numerical procedure based on a modified SDOF model with consideration of the strain rate effect, the method could calculate the yielding delay time of mild steel reinforcement in the analysis of RC elements subjected to air-blast loading. Fitzmaurice and Salim [23] used the SDOF approach to model a polymer sheet as a method for retrofit design. Owing to its simplicity, the SODF approach is also the primary method in analysis of structure responses to blast loads in the design guides such as UFC3-340-02 [24]. The main limitation of SDOF approach is that it cannot model structural failure associated with stress wave propagation such as the direct concrete crushing and spalling failure, and cannot reliably model local structural failure. It is also sometimes difficult to derive a reliable deflection shape when the structure experiences multiple failure modes, and difficult to define failure criteria. These will affect the accuracy of the SDOF analysis results.

To overcome the limitation of SDOF simplification, and to reduce the computational cost of direct numerical modelling, Hao [25] proposed an innovative approach to analyse structural response to blast loadings. In this approach, the structural response is calculated in two steps. In the first step, the forced-response is calculated approximately using the traditional equivalent SDOF approach. The velocity response at the end of the first step is then used as the initial conditions in the second-step free vibration analysis to predict structural response and damage. The displacement response at the end of the forced-vibration phase was neglected because it is very small as the structure had no time to deform yet; and also because it is not straightforward to added initial displacement in the FE model before the free-vibration analysis. It was found that with less than $10 \%$ computational time, the proposed method gives reasonably accurate predictions of RC beam responses to blast loads, especially when the response is flexural response dominate. The prediction of the shear stress in link-reinforcement bars near the supports is, however, less accurate. It is believed that the shear stress near the structural supports is sensitive to structural displacement. Although the structural displacement response is small at the end of the forced vibration phase owing to the usually very short blast loading duration, neglecting the displacement initial condition in the second-step free-vibration analysis in the preliminary study [25] may cause the less reliable predictions of the shear stresses in the link reinforcements. 
In this paper, an improved approach is proposed. Compared to the approach reported by Hao [25], the improved method includes both the displacement and velocity at the end of the first-step forced-vibration phase as the initial conditions in the second-step free vibration analysis. To demonstrate the proposed method, the same simply supported RC beam as in [25] is modelled in detail with the conventional FE approach, and with the proposed method. The results obtained from the detail FE modelling are used as the benchmark to check the reliability of the proposed method. It demonstrates that including displacement response at the end of the forced-vibration phase as the initial condition in the second-step free-vibration response analysis in general improves the prediction accuracy. The proposed method, with substantially less computing time, gives reliable predictions of the beam responses to blast loadings as compared to the traditional FE approach. Parametric calculations are also carried out in this study to estimate the prediction errors on various response quantities and savings on computational times of the proposed two-step method with respect to different blast loading scenarios. The efficiency and accuracy of the proposed two-step approach to predict $\mathrm{RC}$ beam response to blast loads are discussed in this study. Possible further improvement of the method in its prediction accuracy is also outlined.

\section{NUMERICAL MODEL}

In this paper, a simply-supported RC beam is used to demonstrate the proposed method. The $\mathrm{RC}$ beam under study has a rectangular cross section of $320 \times 400 \mathrm{~mm}$ with four longitudinal reinforcement bars of diameter $20 \mathrm{~mm}$. Stirrup reinforcements of diameter $10 \mathrm{~mm}$ are placed along the beam with a constant space of $160 \mathrm{~mm}$. The concrete cover depth is $40 \mathrm{~mm}$. The dimensions of the beam are shown in Figure 1.

Concrete is modelled with isotropic solid elements and reinforcement bars are modelled with beam elements in numerical simulation. Perfect bond between concrete and reinforcements are assumed in the model. Numerical convergence tests were carried out to determine the element size. The results, which are not shown here, indicate that decreasing the mesh size further than $25 \mathrm{~mm}$ has little effect on the numerical results obtained by direct blast response simulation. According to this, an element size of $20 \mathrm{~mm}$, instead of $25 \mathrm{~mm}$, is chosen for the detailed FE modelling in direct blast response simulation in the study for easy modelling of the $40 \mathrm{~mm}$ concrete cover.

An $80 \mathrm{~mm}$ length on each end of the beam is assumed to rest on a rigid support to simulate the simply-supported condition, as shown in Figure 1. In the FE model, Nodes on the left end of beam bottom surface in this range as shown in Figure 2 are constrained for translational movements along the $\mathrm{X}, \mathrm{Y}$ and $\mathrm{Z}$-axis, but free to rotate about the $\mathrm{X}$-axis; at the right end, the nodes in this range are constrained for translational movements along the $\mathrm{X}$ and $\mathrm{Y}$-axis, but free to move along the $\mathrm{Z}$-axis and rotate about the $\mathrm{X}$-axis.

\section{MATERIAL MODEL}

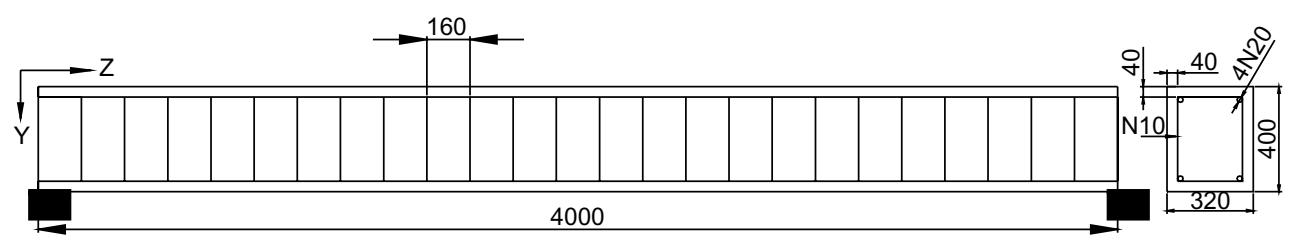

Figure 1. Example RC beam (dimensions in $\mathrm{mm}$ ) 

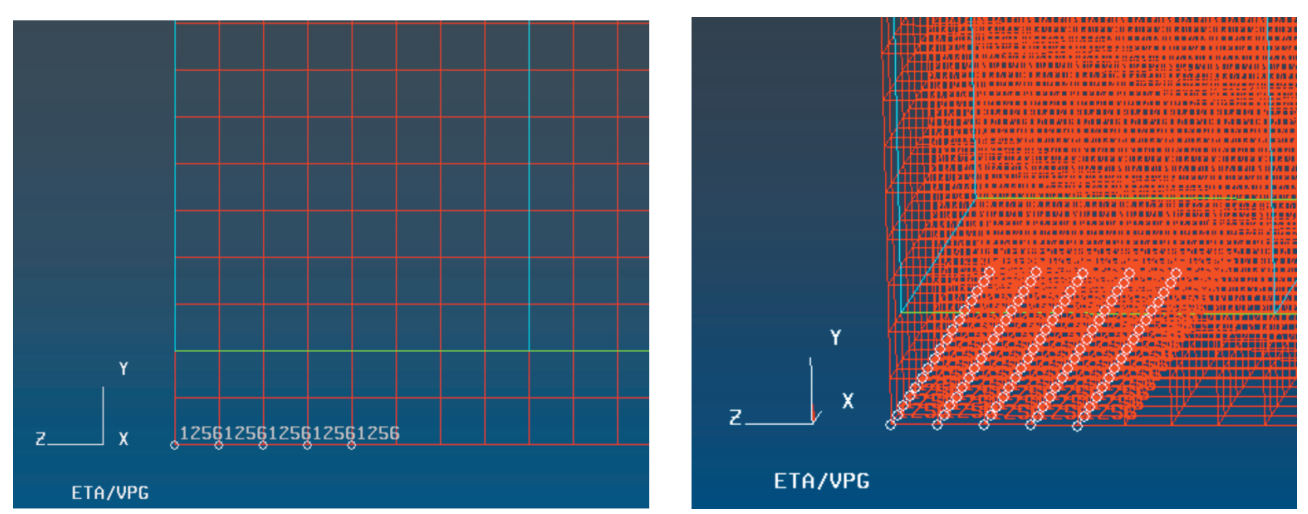

Figure 2. Boundary supports of example beam

In this study, material model 72Rel3 (MAT CONCRETE DAMAGE REL3) in LS-DYNA is chosen to model concrete material. This model was proven yielding reliable predictions of the blast induced concrete structural response [12]. The only parameter needed to define the concrete material model is the unconfined compressive strength of the concrete, which can be easily derived from the experimental test. The concrete material parameters used in this study is given in Table 1. It should be noted that the uniaxial tensile strength and principal failure strain are two erosion criteria defined in the simulation. They are used to erode concrete elements away when either the tensile strength or principal strain reaches these criteria to avoid element tangling and computation overflow. It should be noted that they are not physically based and in fact eroding elements away violates conservation of mass and energy. Therefore it should be used with caution. In previous study, Xu and Lu [13] used the principal tensile strain as the erosion criterion for reinforced concrete. Shi et al. [16] adopted both the maximum shear strain and principle strain as the erosion criteria for simulating concrete material damage. These simulations show a consistent comparison with the relevant experimental observations. In this study, two erosion criteria, i.e., uniaxial tensile stress and principal failure strain as given in Table 1, are adopted. The element will be deleted when either criterion is met.

Table 1. Concrete Material Properties

\begin{tabular}{llll} 
Material & LS-DYNA Model & Input Parameters & Magnitude \\
\hline & MAT_CONCRETE_ & Mass density & $2400 \mathrm{~kg} / \mathrm{m}^{3}$ \\
& Uniaxial compressive & $40 \mathrm{MPa}$ \\
Concrete & $\quad$ strength & \\
& Erosion Criteria & Poisson's ratio & 0.2 \\
& & Uniaxial tensile strength & $5.0 \mathrm{MPa}$ \\
& & Principal failure strain & 0.9 \\
\hline
\end{tabular}

Material model 24 (MAT PIECEWISE LINEAR PLASTICITY) is chosen to model both the longitudinal and stirrup steel. This material model allows user to input a stress strain curve. The material properties of the steel used in the simulation is given in Table 2. It should be noted that elastic-perfect plastic material model is assumed in the present study, and the 
erosion criterion is defined by the failure plastic strain and given in Table 2 .

Table 2. Steel Material Properties

\begin{tabular}{lllr} 
Material & LS-DYNA Model & Input Parameters & Magnitude \\
\hline Steel (for & & Mass density & $7800 \mathrm{~kg} / \mathrm{m}^{3}$ \\
longitudinal & MAT_PIECEWISE_LINEAR_ & Young's Modulus & $200 \mathrm{GPa}$ \\
reinforcement and & PLASTICITY & Poisson's ratio & 0.3 \\
transverse stirrup & & Yield stress & $550 \mathrm{MPa}$ \\
reinforcement) & Erosion criterion & Failure plastic strain & 0.12 \\
\hline
\end{tabular}

Besides the above properties, the strain rate effect is taken into consideration. It is known that, due to the strain rate effect, mechanical properties of materials such as the concrete and steel under impulsive loading differ from those under quasi-static conditions. Such influence on the compressive and tensile strength of concrete and steel is defined by a Dynamic Increase Factor (DIF). In this study, DIF for the concrete compressive strength is defined according to the empirical function provided by CEB-FIP Model Code 1990 [26], that for the concrete tensile strength is defined according to Malvar and Ross [27], and that for steel according to Malvar [28]. DIF for the concrete and steel used in this study are shown in Figure 3.
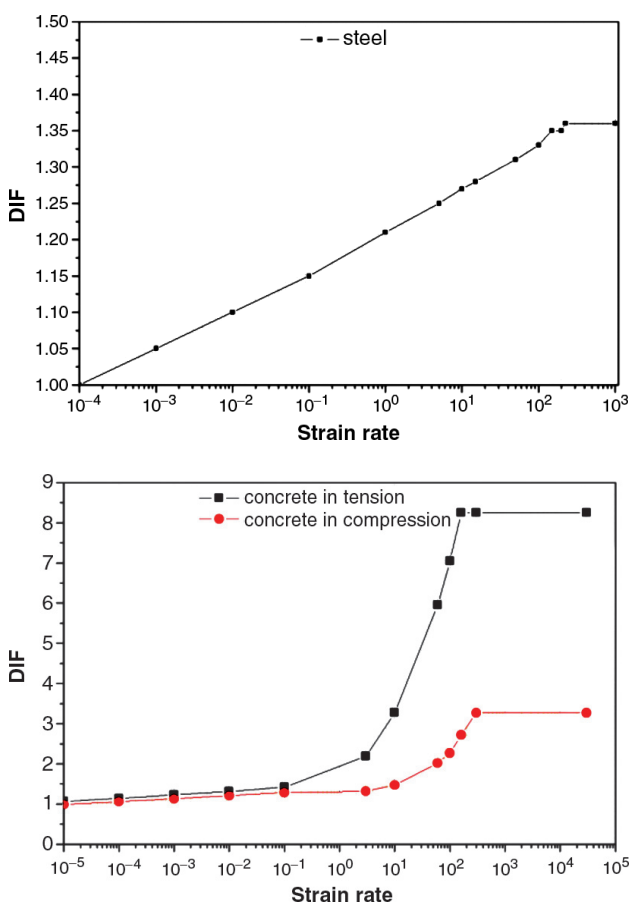

Figure 3. DIF of concrete and steel versus strain rate 


\section{SIMPLIFIED ANALYSIS MODEL}

In this study, the blast load is simplified as a triangular pulse that has the form as follows:

$$
p(t)= \begin{cases}p_{0}\left(1-t / t_{d}\right) & \text { for } t \leq t_{d} \\ 0 & \text { for } t \geq t_{d}\end{cases}
$$

where $t_{d}$ is the blast duration and $P_{0}$ is the initial peak pressure of the blast load.

According to Biggs [29], by following certain deformation shape a simply-supported beam can be simplified into an equivalent SDOF system for analysis. The equivalent system depends on the assumed deflection shape. Figure 4 shows the two commonly used deflection shape in practice. They both represent the beam response primarily in flexural deformation with elastic and plastic deformation assumptions, respectively.
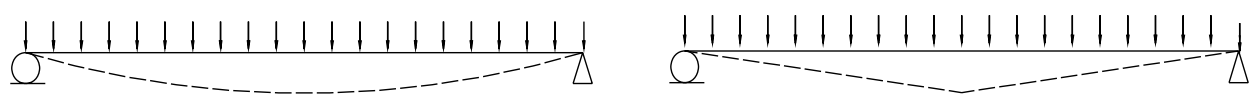

Figure 4. Commonly used elastic and plastic deflection shape

Besides flexural responses, under short duration and high amplitude blast loads, shear failure of beams is also observed. To model shear failure of the beam, a third deflection shape as shown in Figure 5 is also considered in this paper. It should be noted that the shear failure region is not straightforward to define. If the loading duration is very short and amplitude extremely high, the beam tends to suffer direct shear failure. In between of the direct shear failure and flexural failure, beam suffers diagonal shear failure. In this study, it is assumed the beam experiences diagonal shear failure and the shear failure region is $1 / 6$ of the beam length as shown in Figure 5.

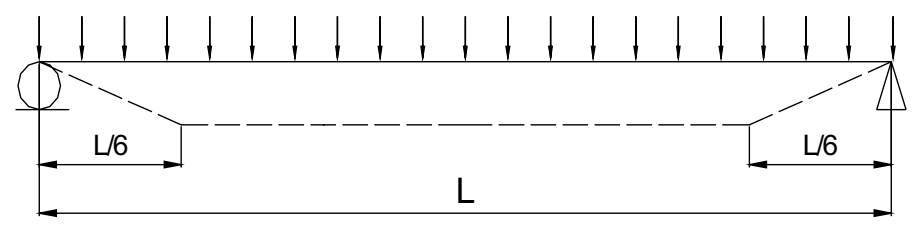

Figure 5. Shear shape mode

These deflection shapes are used in the present study to derive the corresponding equivalent SDOF system for the analysis of beam responses in the forced-vibration phase. The normalized functions for these deflection shapes are:

$$
\begin{aligned}
& \phi(x)=\frac{16}{5 L^{4}}\left(L^{3} x-2 L x^{3}+x^{4}\right) \quad \text { For elastic deformation }
\end{aligned}
$$

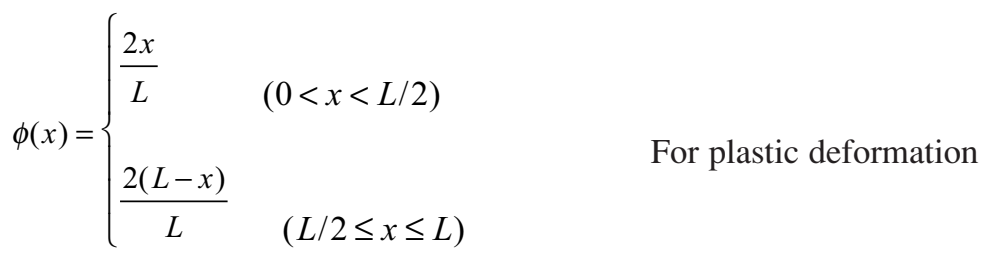




$$
\phi(x)=\left\{\begin{array}{cc}
\frac{6 x}{L} & (0<x \leq L / 6) \\
1 & x \in(L / 6,5 L / 6) \\
\frac{6(L-x)}{L} & (5 L / 6 \leq x \leq L)
\end{array}\right.
$$

The equivalent mass, stiffness and load for the SDOF system can then be calculated as follows based on Biggs [29]:

$$
\begin{gathered}
M_{e}=\int_{0}^{L} \rho(x) \phi^{2}(x) d x \\
P_{e}=\int_{0}^{L} q(x) \phi(x) d x \\
K_{e}=K \frac{P_{e}}{P_{t}}
\end{gathered}
$$

where $K$ is the stiffness of the beam with respect to the deflection at the mid span under the given loading conditions, $q(x)$ is the distributed load along the beam length, $P_{t}$ is total external load acts on the structure.

The above failure functions are verified in some numerical simulations of beam failure modes shown in Figure 6. As shown, when the ratio of blast loading duration to the natural vibration period, $t_{d} / T$, where $T$ is the natural vibration period of the beam is the same, increasing the loading amplitude makes the deflection shape change from flexural elastic, flexural plastic, and combined flexural and shear failure mode as defined above.

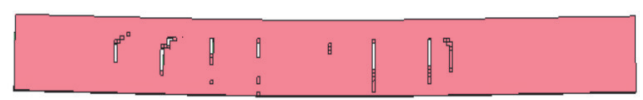

(a) $1 \mathrm{MPat} \mathrm{t}_{\mathrm{d}}=0.25 \mathrm{~T}$

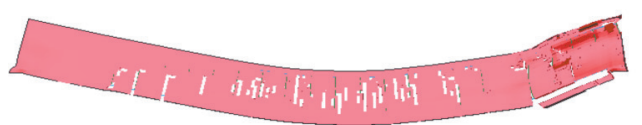

(c) $10 \mathrm{Mpat} \mathrm{t}_{\mathrm{d}}=0.25 \mathrm{~T}$

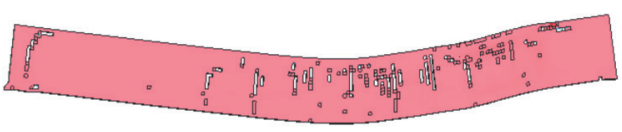

(b) $5 \mathrm{MPa} \mathrm{t}_{\mathrm{d}}=0.25 \mathrm{~T}$

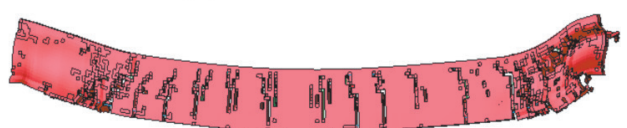

(d) $15 \mathrm{MPa} t_{\mathrm{d}}=0.25 \mathrm{~T}$

Figure 6. Development of response mode when $t_{d}=0.25 \mathrm{~T}$

It should also be noted that under the same blast loading amplitude, with the increment of the loading duration, the structure deflection shape becomes more and more flexural response dominated as shown in Figure 7. 


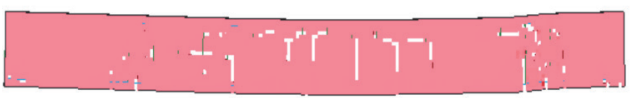

(a) $10 \mathrm{MPat} \mathrm{t}_{\mathrm{d}}=0.05 \mathrm{~T}$

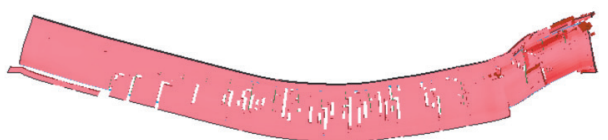

(c) $10 \mathrm{MPa} t_{d}=0.25 \mathrm{~T}$

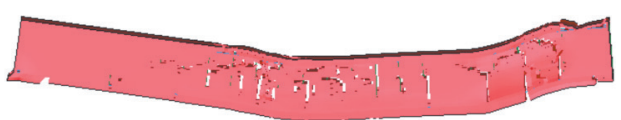

(b) $10 \mathrm{MPa} \mathrm{t}_{\mathrm{d}}=0.1 \mathrm{~T}$

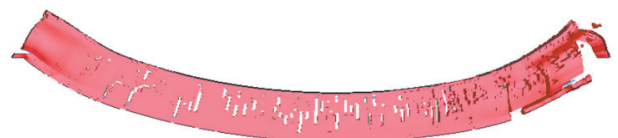

(d) $10 \mathrm{MPa} t_{d}=0.5 \mathrm{~T}$

Figure 7. Development of response mode under $5 \mathrm{MPa}$ blast load

As demonstrated above, the deflection shape depends on both the blast loading amplitude and the ratio of the blast loading duration to beam vibration period. Since the accuracy of the equivalent SDOF analysis depends on how reliable the equivalent system represents the original structure, it is very important to select a proper deflection shape in the analysis. Since there is no quantitative guide available yet on how to select the deflection shape in deriving the equivalent SDOF system, in the present study, the above three deflection shape will be considered in the analysis. Discussions on how well they represent the original beam responses under different blast loading scenarios will be made.

Under the triangular load, the response of a SDOF system can be straightforwardly derived as:

when $\mathrm{t} \leq \mathrm{t}_{\mathrm{d}}$, with zero initial conditions $\mathrm{U}_{\mathrm{t}=0}=0, \mathrm{~V}_{\mathrm{t}=0}=0$

$$
\begin{gathered}
U(t)=\frac{p_{e 0}}{k_{e}}\left(1-\frac{t}{t_{d}}-\cos \omega_{n} t+\frac{\sin \omega_{n} t}{\omega_{n d} t_{d}}\right) \\
V(t)=\frac{p_{e 0}}{k_{e}}\left(\frac{\cos \omega_{n} t-1}{t_{d}}+\omega_{n} \sin \omega_{n} t\right)
\end{gathered}
$$

where $U(t)$ and $V(t)$ are the displacement and velocity response respectively, $P_{e 0}$ is the equivalent maximum force, $\omega_{n}$ is the natural vibration frequency of the equivalent SDOF system.

The displacement and velocity response at the end of the forced vibration phase can be calculated by letting $t=t_{d}$ in the above two equations. The displacement and velocity profiles of the entire beam are then obtained according to the assumed deflection shape used to derive the respective SDOF system. These displacement and velocity profiles are considered as the initial conditions in the second step free vibration analysis. In the second step free vibration analysis, no direct blast force acts on the structure, so larger element size can be used. This will result in substantially less computer memory and computational time. It should be noted that in the previous study by Hao [25] the initial displacement is assumed to be zero in the second step free vibration analysis because the displacement at the end of the first-step forced vibration analysis is very small owing to the very short blast loading duration, and also because it is not straightforward to add initial displacement in the FE model in the free vibration analysis. However, it was found that this simplification resulted in relatively inaccurate predictions of the stirrup stress near the supports. In this extended paper, both the displacement and velocity at the end of the forced vibration phase are considered in the free vibration analysis. The 
influence of the initial displacement response on simulation accuracy is discussed.

To add displacement response at the end of the first-step analysis as the initial condition to the second-step free vibration analysis, the maximum displacement at the mid span is derived from Equation 8. Then through the implicit processor in ANSYS, the target beam is divided into 100 components along the length direction, each component of the FE beam is assigned with a corresponding displacement following the deformation shape assumption defined in Equations 2-4. Then the FE model with initial displacement is transferred into LS-DYNA for the explicit analysis. The initial velocities are assigned to the beam components similarly according to the deformation shape, but it is straightforwardly done in LS-DYNA by directly assigning the velocity to the corresponding nodes. After the initial displacements and velocities of the beam are defined, the second-step free vibration analysis is carried out in LS-DYNA.

\section{INFLUENCE OF THE INITIAL DISPLACEMENT}

In the detailed FE model simulation, blast load is assumed to be uniformly applied on the structure, in order to get accurate structural response, small element size of $20 \mathrm{~mm}$ is used, and the total calculation time for the response is set to be $100 \mathrm{~ms}$. However, when the blast loading is sufficiently large, beam fails before $100 \mathrm{~ms}$ and simulation stops when beam completely collapses. In the simplified free vibration simulation, because no direct blast force acts on the beam, larger element size can be used. In this study, the element size of $40 \mathrm{~mm}$ is chosen because the concrete cover depth is $40 \mathrm{~mm}$. In practical application, it is believed that an element size larger than $40 \mathrm{~mm}$ will result in similar simulation results. This, however, is not verified in the present study, but will be done in the near future. To compare the response between the detailed FE model simulation and the simplified numerical method, gauge points A and B on the reinforcement bars are selected in LS-PREPOST to read the stress time-histories. Figure 8 shows the locations of these points.

Point $\mathrm{A}$ at the middle point of the longitudinal rebar is chosen for the velocity, displacement and longitudinal stress response recording, the displacement, velocity and bending moment at this point are the largest; Point B is selected for the stirrup stress recording because the shear stress reaches the maximum around that point.

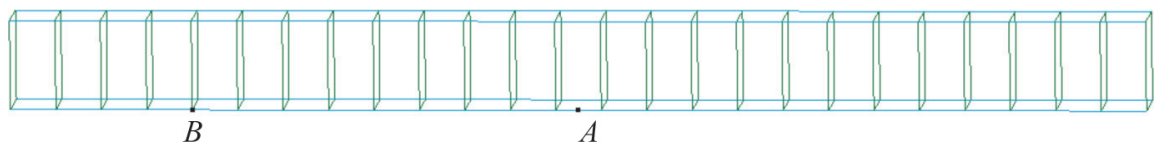

Figure 8. Gauge points on reinforcement bars

To demonstrate the influence of including the initial displacement in the proposed twostep method on its accuracy, a series of simulations are carried out by using the detailed FE model simulation and the proposed method with or without consideration of the initial displacement. All the simulations are conducted with the blast loading amplitude of $10 \mathrm{MPa}$.

\subsection{ELASTIC FLEXURAL DEFORMATION SHAPE ASSUMPTION}

In the proposed simplified numerical method, proper structural deformation assumption is important. Here in this part, elastic deformation shape is assumed. Figure 9 shows the simulated deformation shape of the beam obtained with the three analyses when the peak blast pressure is $10 \mathrm{MPa}$ and duration $\mathrm{t}_{\mathrm{d}}=0.01 \mathrm{~T}, \mathrm{t}_{\mathrm{d}}=0.05 \mathrm{~T}$ and $\mathrm{t}_{\mathrm{d}}=0.1 \mathrm{~T}$, respectively, where $\mathrm{T}$ is obtained as $24.4 \mathrm{~ms}$. Beam failure mode with blast duration $\mathrm{t}_{\mathrm{d}}=0.25 \mathrm{~T}$ and $\mathrm{t}_{\mathrm{d}}=0.5 \mathrm{~T}$ are not presented because the beam completely collapses in all three simulations. However, the stress simulation comparison at point A and B will still be discussed. 


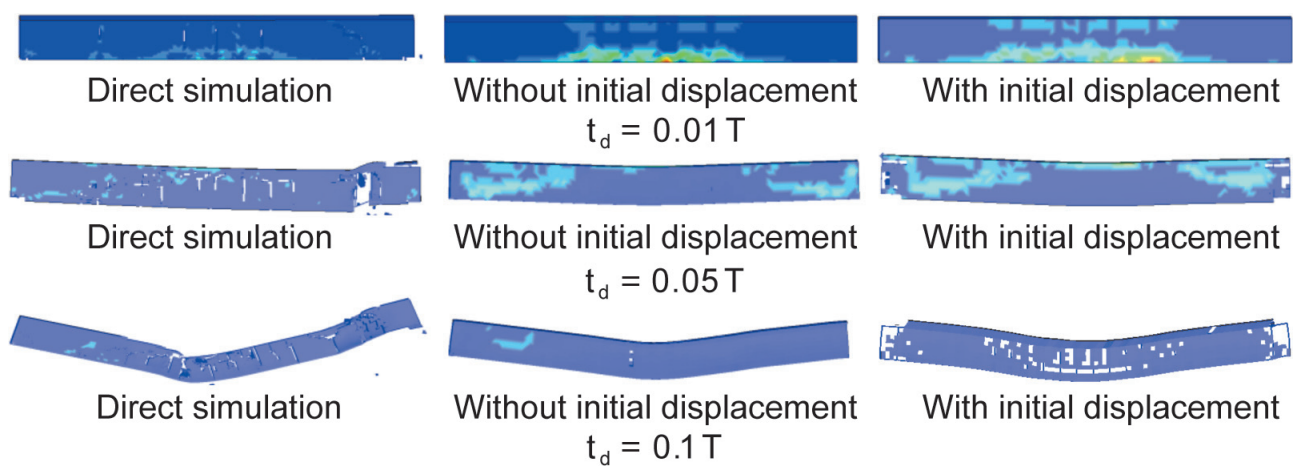

Figure 9. Beam deformation shape at the end of simulation

As shown in Figure 9, with the introduction of the initial displacement, the failure near the supports and at the middle of the beam is better captured by the proposed method as compared to the direct simulation. However the proposed method displays more concrete damage, e.g., in the case with $t_{d}=0.1 \mathrm{~T}$. This is because the concrete material strain rate effect is included in the direct simulation, which results in higher concrete material strength. In the proposed method, the beam starts to vibrate with the given initial displacement and velocity. Implementing the initial displacement already results in some concrete material damage because the initial displacement is added without considering the strain rate effect. Further improvement of the method by incorporating the strain rate effect when adding the initial displacement is deemed necessary. Nonetheless, the proposed method well captures the major features of the RC beam response and damage.

Figure 10 presents response time-histories corresponding to the case with the blast loading duration $t_{d}=0.01 T$. In the figure, the caption 'bench mark' refers to the results from the detailed FE simulation, 'elastic shape' indicates the corresponding results obtained by using the proposed method with elastic flexural deformation shape assumption but without including the initial displacement in the free vibration analysis; 'elastic displacement' is the results obtained from the proposed method utilizing elastic deformation shape assumption and including both the displacement and velocity initial conditions in the second-step free vibration analysis. As shown the proposed methods with or without consideration of the initial displacement yields almost the same structural responses. This is because under this condition, the initial displacement or the displacement at the end of the blast loading phase is quite small (which is $1.976 \mathrm{e}-4 \mathrm{~m}$ at the mid span) because the structure has no time to respond in such a short time, the influence of the inclusion of the displacement is therefore not prominent. As shown, all response quantities at the mid span, i.e., displacement, velocity and longitudinal reinforcement stress are reliably simulated by using the proposed method. The stress in the shear link at point B is, however, poorly predicted by using the proposed method. As will be demonstrated later, this is because of the poor representation of the flexural elastic deformation shape in representing the shear deformation near the beam supports, also possibly because of the stress wave propagation induced by blast load in the beam that is not captured by the proposed method.

To quantitatively analyze the reliability of the proposed method, error between the bench mark results and the results obtained with the simplified method is defined as:

$$
\text { Error }=\frac{\text { benchmark results }- \text { results from proposed method }}{\text { benchmark results }}
$$


From the simulation results, the errors corresponding to the maximum displacement response from the proposed method with or without considering the initial displacement are found to be both about $15 \%$. The errors corresponding to the maximum velocity responses are $14 \%$ and $12 \%$ respectively without or with inclusion of the initial displacement in the simulation. The proposed method with initial displacement also yields better predictions of the longitudinal stress with an error less than $23 \%$ while the error is $30 \%$ if initial displacement is neglected. As shown in Figure 10(d), the proposed method significantly underestimates the maximum stirrup stress with an error larger than $80 \%$. This is because the hoop stress near the support at point B is very sensitive to the deformation shape assumption. With a $10 \mathrm{MPa}$ and $\mathrm{t}_{\mathrm{d}}=0.01 \mathrm{~T}$ blast load, shear failure mode contributes significantly to the beam failure. Using the elastic flexural deformation assumption failed to give reliable predictions of the stress in hoop reinforcement at point $\mathrm{B}$.

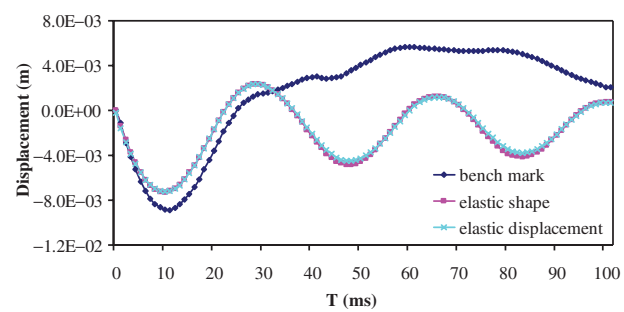

(a)

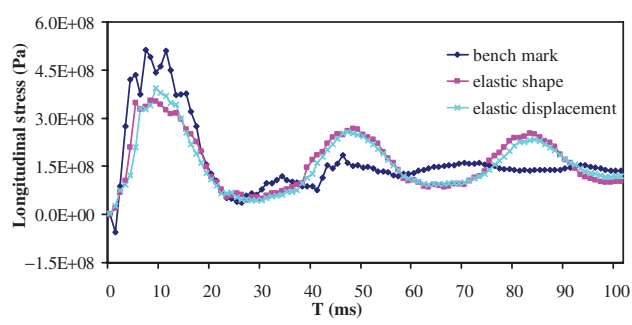

(c)

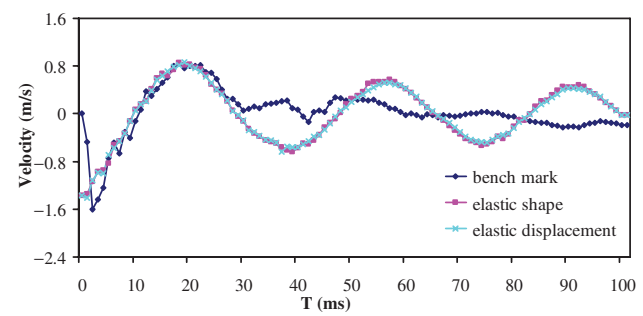

(b)

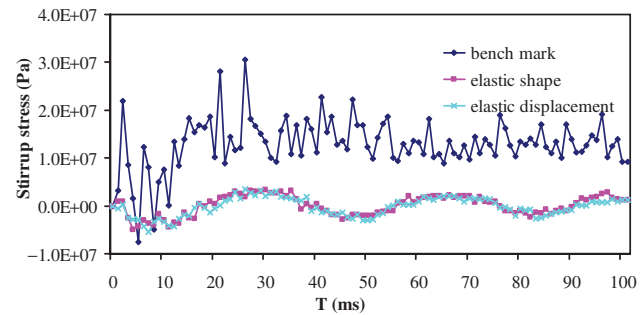

(d)

Figure 10. Structural response to blast load with $t_{d} / T=0.01$, (a) displacement time-history at point $A$; (b) velocity time-history at point $A$; (c) longitudinal stress time-history at point $A$; (d) stirrup stress time-history at point $B$

When the blast load duration extends to half of the natural vibration period of the beam, i.e., $t_{d}=0.5 \mathrm{~T}$, the displacement at the end of the loading phase at point A can be derived as $0.15 \mathrm{~m}$ from Equation 8. In this case, the beam collapses from all three simulations. Therefore it is meaningless to discuss the displacement and velocity response. Only the stress simulation results will be presented here.

From Figure 11(a), it can be seen that when the initial displacement is considered, the simulation yields good prediction of the stress time-history in longitudinal bar as compared with the benchmark result. If only velocity is considered, although the proposed method also gives good prediction of the maximum longitudinal stress, the stress-time history does not compare well. As shown, in this case, the longitudinal stress suddenly drops to zero at about $32 \mathrm{~ms}$, indicating the breakage of the steel bar. In detailed FE simulation and in the simulation with consideration of initial displacement, the steel bar does not break although 
intensive concrete material damage is observed. From Figure 11(b), it can be seen that the proposed method with or without considering the initial displacement gives reliable predictions of the stirrup stress at point $\mathrm{B}$, with the largest error less than $10 \%$, indicating in this case the flexural response dominates the beam response because the loading duration is relatively long.

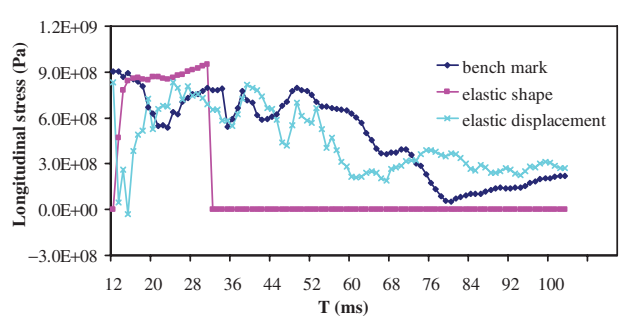

(a)

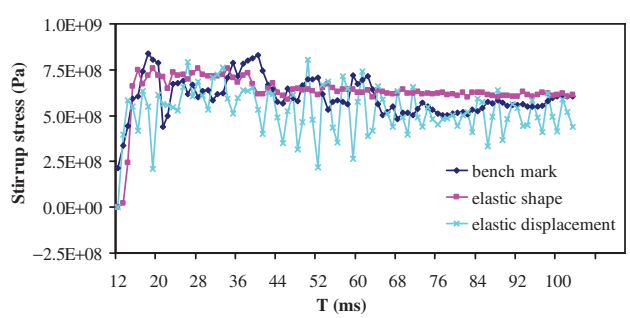

(b)

Figure 11. Structural response to blast load with $t_{d} / T=0.5$, (a) longitudinal stress time-history at point $A$; (b) stirrup stress time-history at point $B$

The above results demonstrate that, as expected, including initial displacement improves the accuracy of the proposed method. The reliability of the method, however, very much depends on the assumption of beam deflection shape. Influence of different deformation shape assumptions on the accuracy of the proposed method will be discussed in the following sections.

\subsection{PLASTIC FLEXURAL DEFORMATION SHAPE ASSUMPTION}

The above results are recalculated in this section with plastic flexural deformation assumption. Figure 12 shows the failure modes obtained from the detailed FE simulation and the proposed method with or without including initial displacement in the free-vibration analysis. Similar observations made in Figure 9 can also be drawn here, i.e., including initial displacement in the second-step free vibration analysis gives relatively better beam deformation and failure predictions.

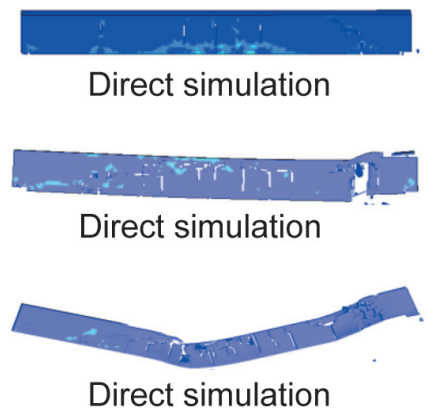

Figure 12. Beam deformation shape at the end of simulation

Figure 13 shows the comparisons of the simulated displacement, velocity, longitudinal and hoop stress obtained from the three approaches. As shown, similar results as those given 
in Figure 10 are obtained, indicating elastic and plastic flexural deformation shape assumptions result in similar structural response predictions.

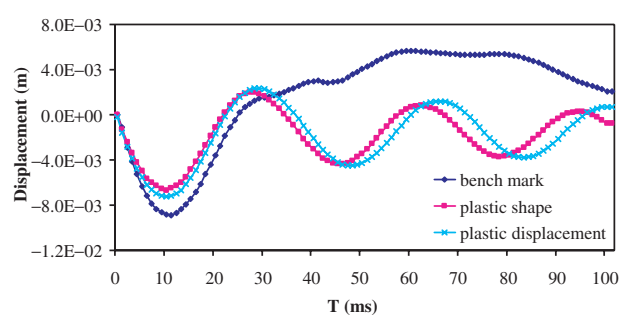

(a)

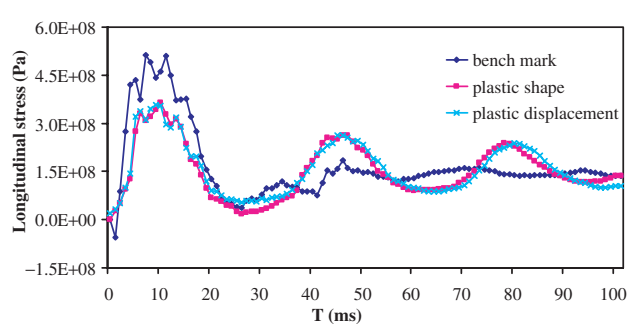

(c)

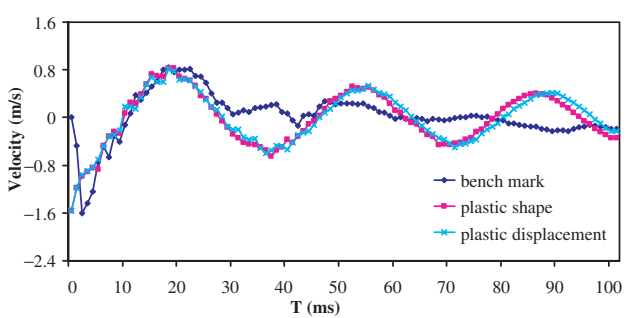

(b)

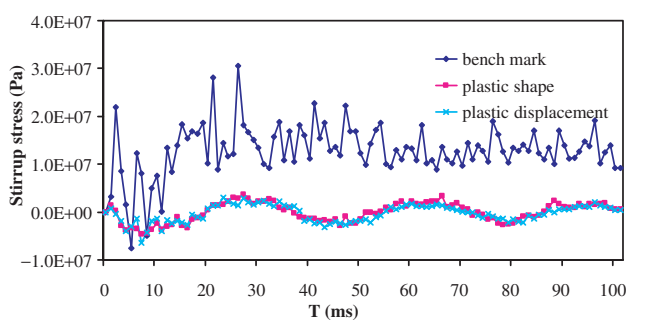

(d)

Figure 13. Structural response to blast load with $t_{d} / T=0.01$, (a) displacement time-history at point $A$; (b) velocity time-history at point $A$; (c) longitudinal stress time-history at point $A$; (d) stirrup stress timehistory at point B

Similar to the case with the elastic flexural deformation assumption, when the blast load duration is $t_{d}=0.5 \mathrm{~T}$, All three approaches predicted beam collapse. Therefore only stresses in longitudinal and hoop reinforcements are presented and compared. It can be seen in Figure 14 that the introduction of the initial displacement yields better prediction of the longitudinal stress. For stirrup stress at point B, with or without including the initial displacement all give satisfying simulations of the stresses in reinforcement bars with the maximum error less than $15 \%$.

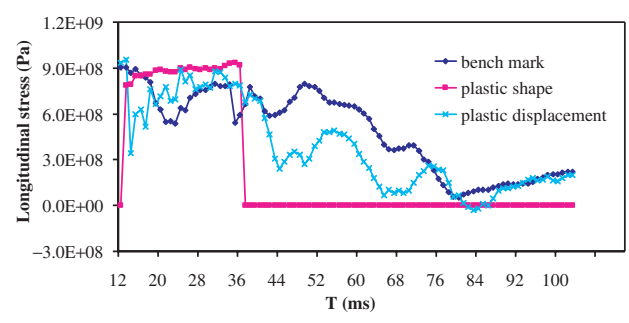

(a)

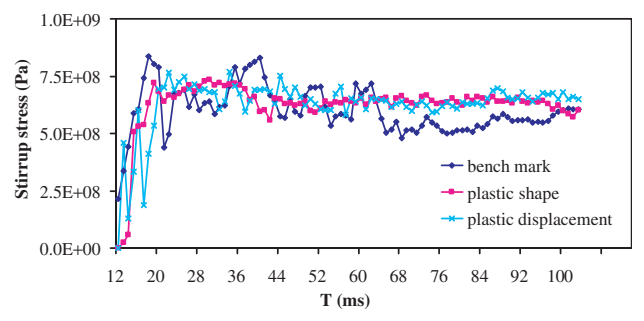

(b)

Figure 14. Structural response to blast load with $t_{d} / T=0.5$, (a) longitudinal stress time-history at point $A$; (b) stirrup stress time-history at point $B$ 


\subsection{SHEAR DEFORMATION SHAPE ASSUMPTION}

This section presents and compares the results obtained by assuming shear failure deformation shape. The comparison of the deformation shapes from the detailed FE simulation, initial velocity only simulation and initial displacement included simulation is shown in Figure 15. As shown, the proposed method with or without including the initial displacement well captures the failure mode of the beam. However, including initial displacement better predicts the concrete material failure.

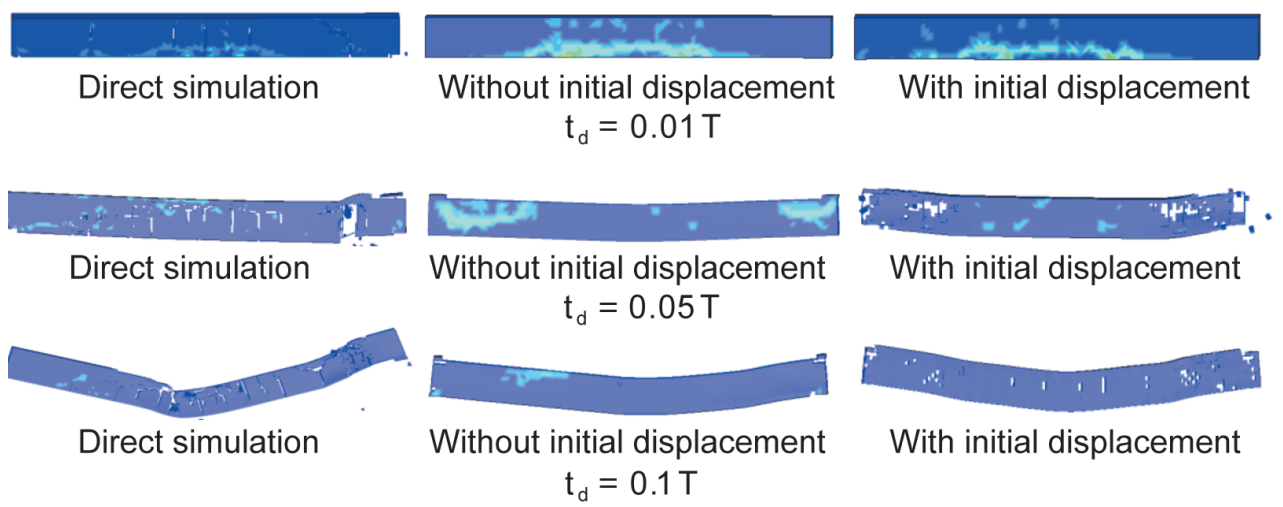

Figure 15. Beam deformation shape at the end of simulation

Figure 16 shows the time-histories of the structural response when the blast loading duration is $t_{d}=0.01 \mathrm{~T}$. As shown, shear deformation shape gives very good predictions of the displacement, velocity and longitudinal stress in reinforcement bars at the mid span of the beam. As compared to those obtained with flexural deformation shape assumptions, shear deformation shape assumption yields more accurate predictions. This is because, as discussed above, the structural response is dominated by shear deformation because beam has no time to experience flexural deformation in such a short time. In this case, the error corresponding to the maximum displacement response is $5.6 \%$. It is $2.0 \%$ for the maximum velocity response, and is below $20 \%$ for the longitudinal stress. As shown in Figure 16(d), using the shear deformation shape, the stirrup stress is also reliably predicted if the initial displacement is included in the proposed method. The largest error is $37 \%$, a significant improvement in the prediction accuracy as compared with those obtained with flexural deformation shape assumption.

Figure 17 compares the stresses in longitudinal and hoop reinforcement bars at points A and $\mathrm{B}$ obtained when $t_{d}=0.5 \mathrm{~T}$. As shown, on contrary to the results presented above, including initial displacement does not improve the prediction accuracy of the stresses in reinforcement bars. One possible reason is that in this case the displacement response at the end of loading phase is quite large. The current approach of implementing the initial displacement to the beam causes quite significant concrete material damage as compared to the direct simulation since the concrete material strain rate effect is not considered when implementing the initial displacement for free vibration analysis. Another possible reason is that the damage of the beam incurred during the loading phase is not considered in the second-step free vibration analysis. Further analyses of these effects are deemed necessary. Nonetheless, the peak stresses predict by the proposed method are reasonably accurate. The errors for the longitudinal stress simulation at point $\mathrm{A}$ are $-2.0 \%$ (negative means 
overestimation) or $2.0 \%$ without or with considering the initial displacement in the calculations. For stirrup stress, the corresponding errors are $6.2 \%$ and $-4.7 \%$, respectively.

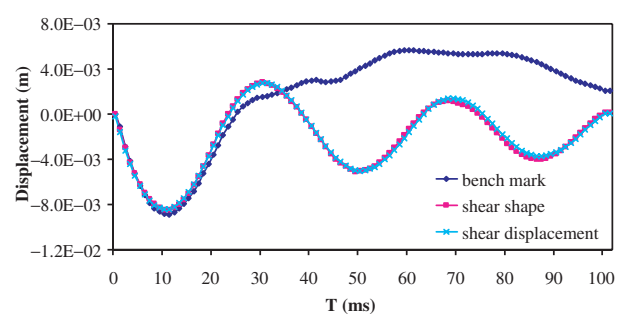

(a)

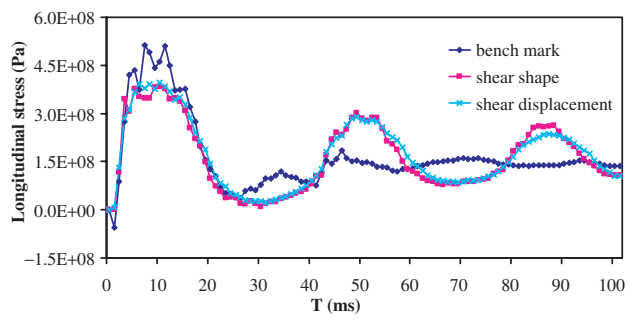

(c)

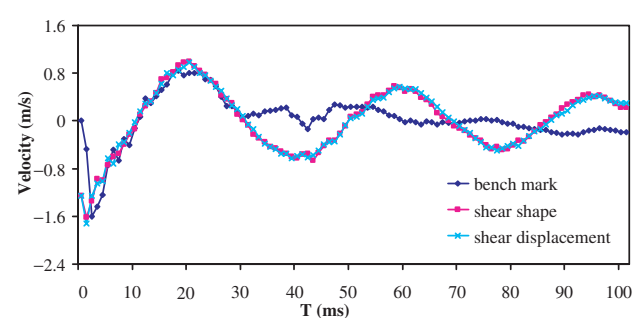

(b)

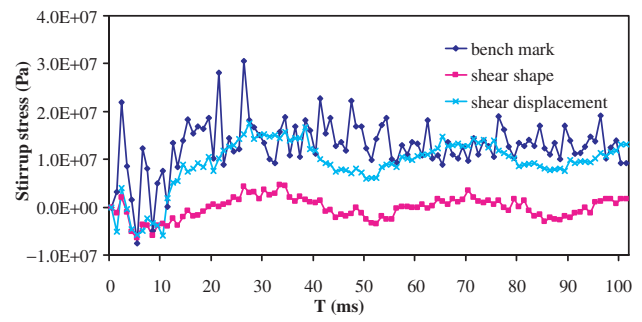

(d)

Figure 16. Structural response to blast load with $t_{d} / T=0.01$, (a) displacement time-history at point $A$; (b) velocity time-history at point $A$; (c) longitudinal stress time-history at point $A$; (d) stirrup stress timehistory at point B

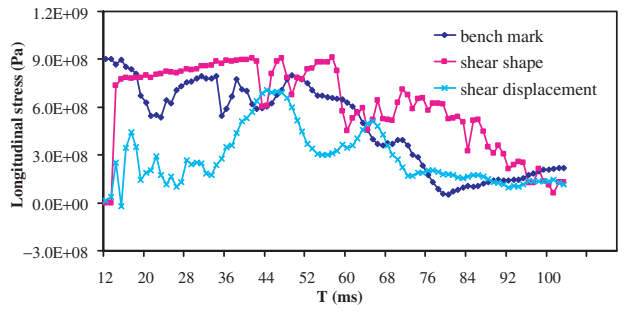

(a)

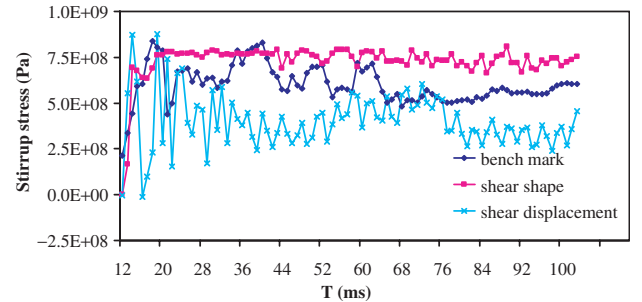

(b)

Figure 17. Structural response to blast load with $\dagger_{d} / T=0.5$, (a) longitudinal stress time-history at point $A$; (b) stirrup stress time-history at point $B$

The above results demonstrate that including initial displacement will in general improve the accuracy of the proposed method. The prediction accuracy highly depends on deformation shape assumption. With different blast duration ratio $t_{d} / T$, different deformation shape assumption needs to be utilized in order to give better simulation results. 


\section{INFLUENCE OF BLAST LOADING SCENARIOS}

This section investigates the influence of blast loadings with different amplitudes and duration on the simulation accuracy of the proposed method. Since including initial displacement in general improves the prediction accuracy, hereafter the initial displacement is included in all the simulations.

\section{1 $1 \mathrm{MPa}$ BLAST LOAD WITH DIFFERENT LOADING DURATION}

Figure 18 shows the beam deflections obtained from direct FE simulations when the blast loading amplitude is $1 \mathrm{MPa}$ and duration varies from $0.01 \mathrm{~T}$ to $0.5 \mathrm{~T}$. As shown, the beam experiences primarily the shear deflection when blast loading duration is short and flexural deflection when the loading duration is relatively long. When the loading duration is very short, the beam response is primarily elastic. Concrete cracks first appear at the mid span of the beam when $t_{d}=0.05 T$. Further increase of the loading duration results in more spread concrete cracks along the beam.

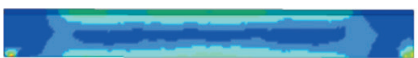

(a) $t_{d}=0.01 T$

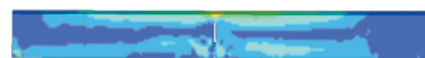

(b) $t_{d}=0.05 T$

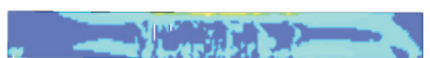

(c) $t_{d}=0.1 T$

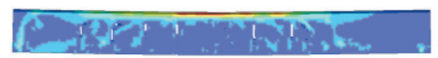

(d) $t_{d}=0.25 T$

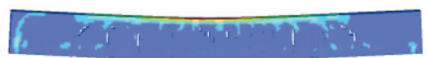

(e) $t_{d}=0.5 T$

Figure 18. Deformation shape of the beam under 1 MPa blast Load

\subsubsection{Responses when $t_{d} / T=0.01$}

When the blast loading duration is short compared to the beam's natural vibration period, as in this case, $t_{d} / T=0.01$, from the response time-histories shown in Figure 19, it can be observed that all three beam deformation shape assumptions give good predictions of the responses at the mid spans, and shear deformation assumption yields only slightly better predictions. The maximum errors for mid span displacement response from the three methods are $2.5 \%$ for shear deformation assumption; $7.4 \%$ for elastic flexural deformation assumption and $14.7 \%$ for plastic flexural deformation assumption. The same errors are obtained for the mid span velocity responses. The errors corresponding to the stresses in longitudinal bar are larger, and they are 18\% for shear deformation assumption, and $32 \%$ and $40 \%$ respectively for the elastic and plastic flexural deformation assumptions. The shear deformation shape assumption results in slightly better predictions because the beam responses are dominated by shear deformations during the loading phase as beam has no time to experience significant flexural deformation in such a short time period.

However, unlike the good predictions of the responses at the mid span, none of the three deformation shape assumptions yield accurate predictions of the hoop stress at point $\mathrm{B}$. This may be explained by the wave propagation phenomenon, blast loads with extremely short duration will induce stress wave propagation in the structure, as well as structural responses. Compared to those shown in Figure 16d, the shear deformation shape assumption with inclusion of the initial displacement gives reasonable prediction of stresses in hoop reinforcement at point $B$ when the blast loading duration is also $t_{d}=0.01 T$, poor simulation is obtained in this case when the blast loading amplitude is smaller, i.e., $1 \mathrm{MPa}$ as compared 
to $10 \mathrm{MPa}$. This is because in this case with a smaller blast load, the structural response of the beam is relatively insignificant as compared to the stress wave propagation. The response quantities at the mid span is governed by the structural response, therefore they are reliably predicted. But the stress in hoop reinforcement at point B is significantly affect by the stress wave propagation, therefore the proposed method, which is structural response based, fails to yield reliable predictions. It gives relatively better prediction when the blast loading amplitude is larger because more significant structural response as compared to the stress wave propagation. Further study of the influence of stress wave propagation on stresses in hoop reinforcement bars is necessary.

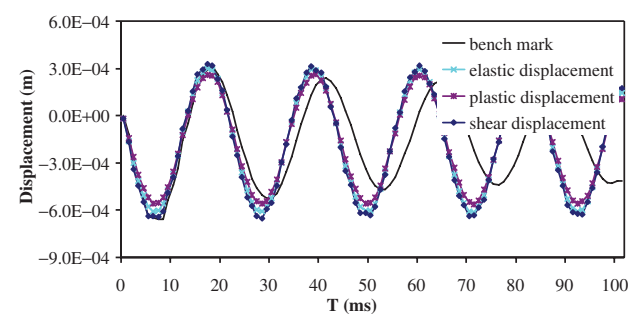

(a) Displacement

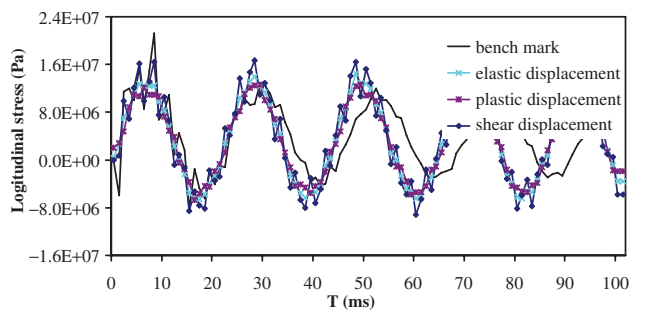

(c) Longitudinal stress

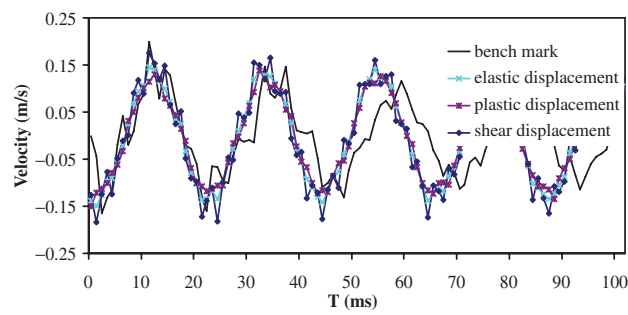

(b) Velocity

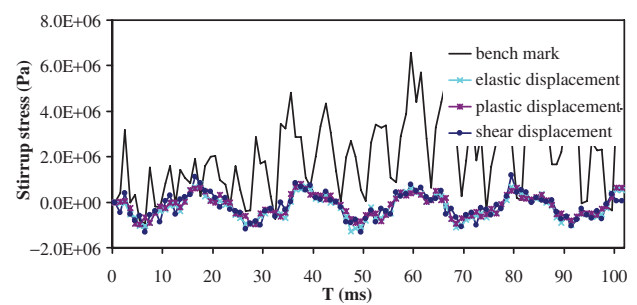

(d) Stirrup stress

Figure 19. Structural response to blast load of amplitude $1 \mathrm{MPa}$ and duration 0.011

\subsubsection{Responses when $T_{d} / T=0.5$}

As shown in Figure 18(e), when the blast loading duration is $t_{d}=0.5 T$, the beam responds primarily in flexural mode. Thus it can be expected that the simulations with flexural deformation assumptions will give comparably better results. This can be verified in Figure 20. From Figure 20(a), it can be noted that the simulations utilizing the elastic and plastic flexural deformation shapes yield better predictions than the shear deformation assumption of the longitudinal stress at point A, with an error of $24 \%$ and $10 \%$ respectively for the maximum stresses. The shear deformation shape assumption does not yield good predictions with the error corresponding to the maximum stresses larger than 50\%. As shown in Figure 20(b), the elastic flexural deformation assumption gives the most accurate prediction of hoop stress at point $B$ with an error less than $4 \%$; followed by the plastic flexural deformation assumption with an error of $30 \%$. However, the shear deformation shape assumption overestimates the maximum hoop stress with an error larger than $51 \%$. 


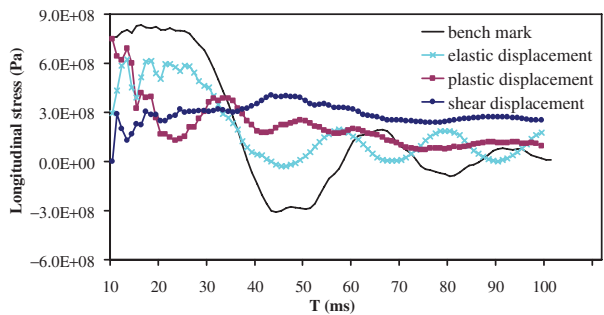

(a) Longitudinal stress

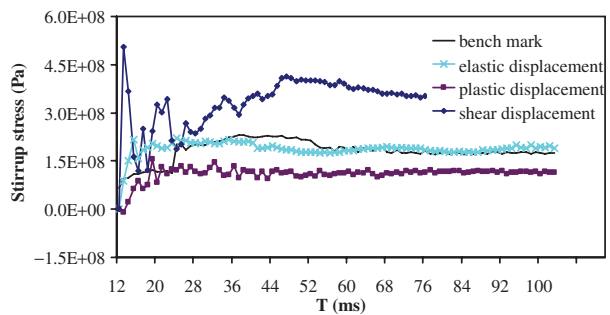

(b) Stirrup stress

Figure 20. Structural response to blast load of amplitude $1 \mathrm{MPa}$ and duration $0.5 \mathrm{~T}$

These results demonstrate that when the blast loading duration is relatively short, beam responds primarily with shear deformation, and shear deformation shape assumption gives better predictions. On the other hand, when blast loading duration is relatively long, beam responds primarily in flexural mode, and flexural deformation shape assumption therefore leads to a better predictions.

\subsection{MPa BLAST LOAD WITH DIFFERENT LOADING DURATION}

Figure 21 shows the deformation shape of the beam subjected to blast load of $5 \mathrm{MPa}$ peak pressure and different duration. As shown, when the blast loading duration is short, i.e., $t_{d} / T \leq 0.05$, the beam deforms primarily with a shear deformation mode; when $t_{d} / T>0.05$, flexural deformation dominates.

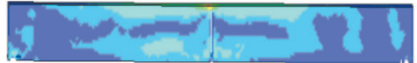

(a) $t_{d}=0.01 T$

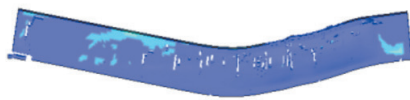

(d) $t_{d}=0.25 T$

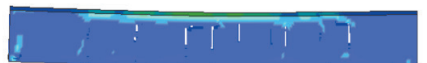

(b) $t_{d}=0.05 T$

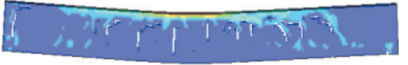

(c) $t_{d}=0.1 T$

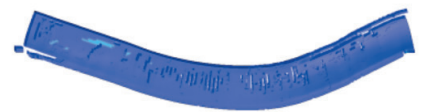

(e) $t_{d}=0.5 T$

Figure 21. Deformation shape of the beam under 5 MPa blast load

\subsubsection{Responses when $T_{d} / T=0.01$}

As shown in Figure 22, the shear deformation assumption yields more accurate simulation results. The errors corresponding to the maximum displacement response at the mid span of the beam are $18 \%, 30 \%$ and $2.8 \%$, respectively for the elastic flexural, plastic flexural and shear deformation shape assumption. For longitudinal stress at point $\mathrm{A}$, the error corresponding to the shear deformation shape assumption is $42 \%$ while the other two deformation shape assumptions give errors larger than $70 \%$. For stirrups stress, the errors for the elastic flexural, plastic flexural and shear deformation shape assumptions are respectively $57 \%, 53 \%$ and $35 \%$. The shear deformation shape assumption gives better predictions of the stresses in hoop reinforcement bars in this case as compared to those shown in Figure 19 because significant structure responses as compared to the stress wave propagation in the beam is induced with a larger blast load. 


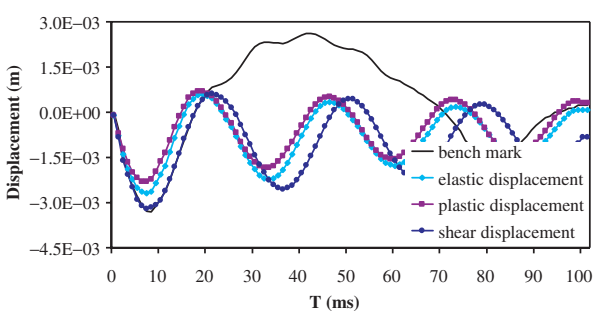

(a) Displacement

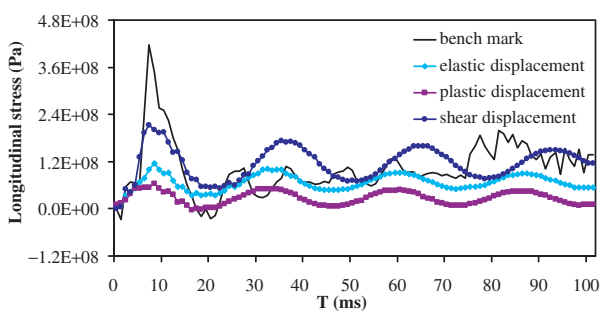

(c) Longitudinal stress

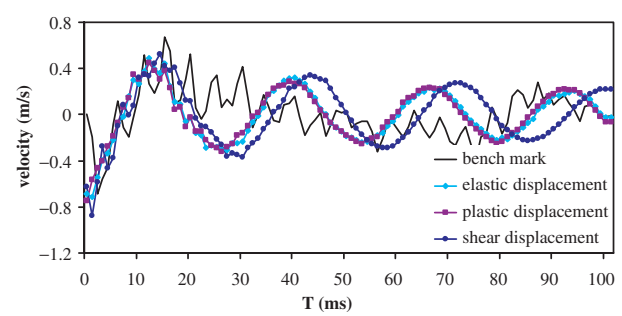

(b) Velocity

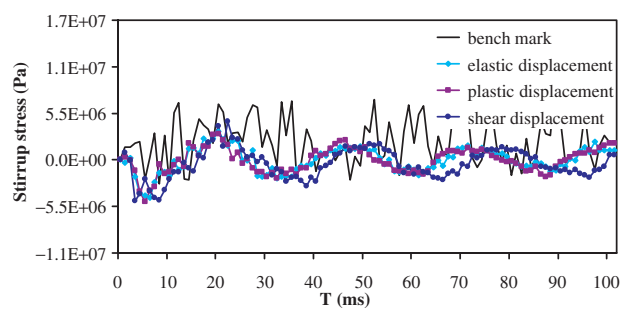

(d) Stirrup stress

Figure 22. Structural response to blast load of amplitude $5 \mathrm{MPa}$ and duration $0.01 T$

\subsubsection{Responses when $t_{d} / T=0.5$}

When the blast loading duration is $0.5 \mathrm{~T}$, the plastic flexural failure mode dominates beam response. Thus the simulation utilizing the plastic flexural deformation assumption yields better predictions of the beam responses as shown in figure 23. The errors corresponding to the maximum longitudinal stresses at mid span from the elastic and plastic flexural deformation assumptions are $2.5 \%$ and $-4 \%$, respectively. The shear deformation shape does not give reliable predictions of the longitudinal stress at mid span. The corresponding error is larger than $50 \%$.

The shear deformation shape assumption gives the least accurate prediction of the hoop stress as well, with an error of $-12 \%$. Whereas the errors from the elastic and plastic flexural deformation shapes are $7.5 \%$ and $2.4 \%$, respectively.

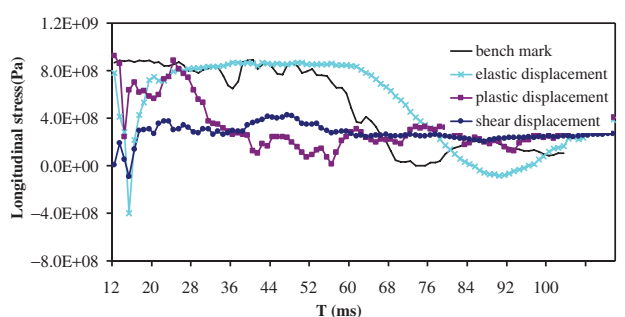

(a) Longitudinal stress

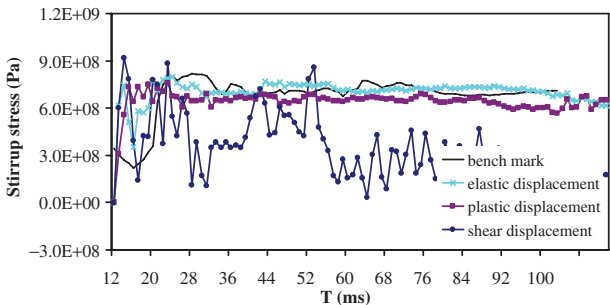

(b) Stirrup stress

Figure 23. Structural response to blast load of amplitude $5 \mathrm{MPa}$ and duration $0.5 \mathrm{~T}$ 
The above results demonstrate again that the primary structural response mode depends on blast loading amplitude and duration. In general, when the blast loading duration is small, shear deformation dominates the beam response mode, while flexural deformation dominates the beam response mode when the blast loading duration is relatively long. The proposed method yields better beam response predictions if a proper deformation shape is assumed in the analysis.

\section{PARAMETRIC STUDY}

In this section, a series of simulations are carried out to define the errors of the proposed method with different deformation shape assumptions corresponding to blast loads of different amplitudes and duration. As can be noticed above, the proposed method always gives better predictions of the displacement and velocity response at the mid span of the beam than stresses in longitudinal and hoop reinforcement bars. Here only the errors in reinforcement bars are presented and discussed.

Figure 24 shows the prediction errors of the proposed method with different deformation shape assumptions corresponding to the blast loads of amplitude $1 \mathrm{MPa}$ and varying loading duration. It can be noticed that, for longitudinal stress at point A and hoop stress at point B, when blast duration $t_{d} / T \leq 0.05$, shear deformation assumption gives better prediction. With the increase of the blast loading duration, the accuracy of the shear deformation shape assumption deteriorates. When $\mathrm{t}_{\mathrm{d}} / \mathrm{T} \geq 0.1$, flexural deformation shape assumptions give better predictions than shear deformation shape assumption. Further, when $t_{d} / T=0.5$, the plastic flexural deformation shape assumption gives the best predictions. If proper deformation shape is adopted, the largest errors corresponding to the stresses in longitudinal reinforcement bars is within 15\%, and those for the hoop stresses at point B is within $100 \%$.

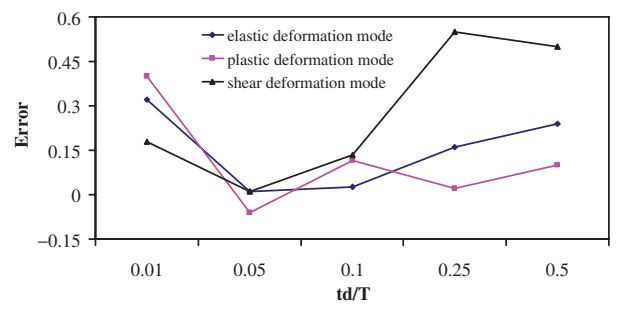

(a) Longitudinal stress error

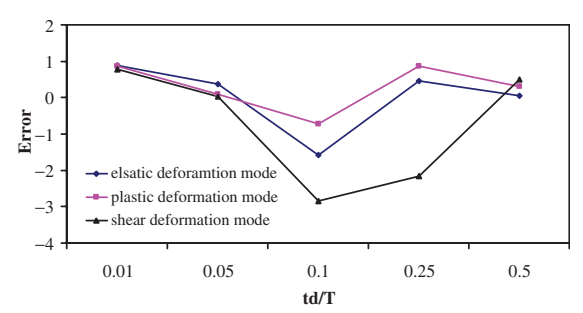

(b) Stirrup stress error

Figure 24. Prediction errors corresponding to 1 MPa blast load

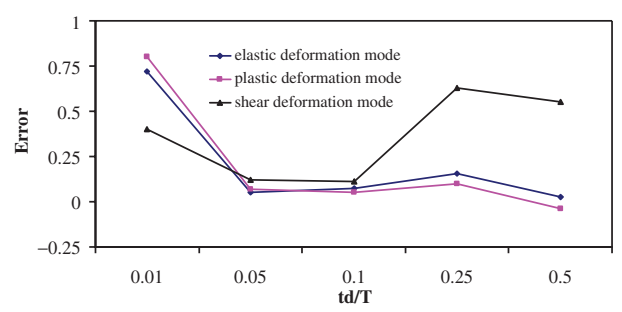

(a) Longitudinal stress error

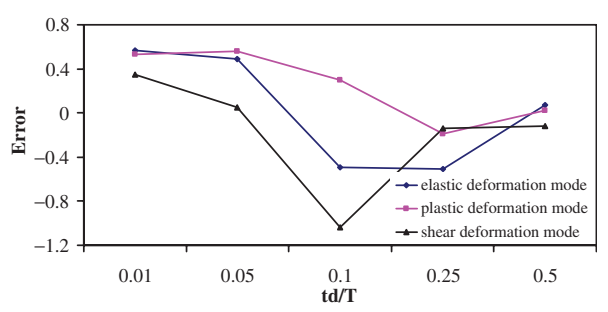

(b) Stirrup stress error

Figure 25. Prediction errors corresponding to 5 MPa blast load 
When the blast loading amplitude is $5 \mathrm{MPa}$, similar observations made above can be drawn here again. As shown in Figure 25, when $t_{d} / T \leq 0.05$, shear deformation shape assumption gives better predictions, while flexural deformation shape assumptions yield more reliable predictions when $t_{d} / T \geq 0.25$.

\section{SIMULATION TIME}

The main advantage of the proposed method is to reduce the computational cost for conducting analysis of the response of structures to blast loads. The proposed method which only needs to simulate the "free vibration phase" allows for the use of larger elements, leading to a decrease in the number of elements in the FE model, therefore less computer memory and computation time.

In this study, the computer used for the analysis has a core processor of Intel(R) Core (TM) 2 DUO, and a processing speed of $3.16 \mathrm{GHz}$ and $3.00 \mathrm{~GB}$ of RAM. Table 3 shows the number of elements and nodes in both the bench mark and simplified models. It should be noted that in this study the element size is chosen as $40 \mathrm{~mm}$ for easy modelling of the concrete cover. In practice, larger element size can be used, which will result in further reductions of the number of elements in the model.

Table 3. No. of elements in beam models

No. of Elements

No. of nodes

\begin{tabular}{lllll}
\hline & $\begin{array}{l}\text { Benchmark } \\
\text { Model }\end{array}$ & $\begin{array}{l}\text { Proposed } \\
\text { Model }\end{array}$ & $\begin{array}{l}\text { Benchmark } \\
\text { Model }\end{array}$ & $\begin{array}{l}\text { Proposed } \\
\text { Model }\end{array}$ \\
\hline $\begin{array}{l}\text { Concrete } \\
\text { solid element }\end{array}$ & 64000 & 8000 & 71757 & 9999 \\
\hline $\begin{array}{l}\text { Long. Steel } \\
\text { beam element }\end{array}$ & 800 & 400 & 804 & 404 \\
$\begin{array}{l}\text { Trans. Steel } \\
\text { beam element }\end{array}$ & 1456 & 728 & 1456 & 728 \\
\hline
\end{tabular}

Table 4 compares the computer times for the direct FE simulation and the analysis with the proposed method when the peak blast load is $5 \mathrm{MPa}$. As can be noticed, the proposed method is significantly more efficient in predicting the beam responses.

Table 4. Computer time for simulations of beam response to $5 \mathrm{MPa}$ blast load (minutes)

\begin{tabular}{lccccc} 
Simulation $/ \mathbf{t}_{\mathbf{d}} / \mathbf{T}$ & $\mathbf{0 . 0 1}$ & $\mathbf{0 . 0 5}$ & $\mathbf{0 . 1}$ & $\mathbf{0 . 2 5}$ & $\mathbf{0 . 5}$ \\
\hline pure blast simulation & 50 & 56 & 60 & 88 & 91 \\
\hline Initial velocity only & 3.1 & 3.2 & 3.5 & 3.5 & 4 \\
\hline Initial displacement included & 3.6 & 4 & 4.25 & 5.25 & 5.75 \\
\hline
\end{tabular}

As listed in Table 4, the detailed FE model simulation time is about 1 to 1.5 hour depending on the blast loading duration, whereas the simulation time of the proposed method is about 3 minutes if the initial displacement is not included, or 4 to 5 minutes by including 
the initial displacement. The time saving is over $90 \%$. It is expected that more savings can be achieved when the structural model is larger. This saving is substantial in practice. Moreover, in view of the many uncertainties in predicting the blast loadings and reliable modelling of structural parameters and damage, the prediction error of less than $100 \%$ is usually acceptable in practical application. It should be noted that the proposed method will need to perform pre-analysis of the structure responses based on SDOF approach. This preanalysis can be straightforwardly done based on closed-form solutions defined in Equations 8 and 9. The equivalent SDOF system parameters can also be easily obtained through design charts in UFC3-340-02 [24]. In view of these, the proposed method has a great application potential.

\section{CONCLUSIONS}

A detailed investigation has been carried out on the feasibility and reliability of an innovative simplified numerical method for the prediction of structural response to blast loads. The accuracy of the proposed method in simulating beam responses to blast loads of different amplitudes and duration is investigated. Based on intensive numerical simulation results, it is found that the proposed method can give reliable predictions of beam responses to blast loads at only about less than $10 \%$ computational time. The great application potential of the proposed method is demonstrated. Further study is underway to include damage incurred in the structure during the loading phase, and strain rate effect on structural materials when starting the free-vibration analysis to increase the prediction accuracy of the proposed method.

\section{ACKNOWLEDGEMENTS}

The authors wish to acknowledge the financial supports from the Australian Research Council (ARC) under grant number DP1096439 for carrying out this research. The first author also wishes to acknowledge China Scholarship Council and the University of Western Australia (UWA) for providing scholarships for him to pursue PhD study in UWA.

\section{REFERENCES}

1. Maji, A.K., Brown, J.P., and Urgessa, G.S., "Full-scale testing and analysis for blast-resistant design". Journal of Aerospace Engineering, 2008. 21(4): p. 217-225.

2. Schenker, A., et al., "Full-scale field tests of concrete slabs subjected to blast loads". International Journal of Impact Engineering, 2008. 35(3): p. 184-198.

3. Smith, P.D., et al., "Small-Scale Models of Complex-Geometry for Blast Overpressure Assessment". International Journal of Impact Engineering, 1992. 12(3): p. 345-360.

4. Dennis, S.T., Baylot, J.T., and Woodson, S.C., "Response of 1/4-scale concrete masonry unit (CMU) walls to blast". Journal of Engineering Mechanics-Asce, 2002. 128(2): p. 134-142.

5. Assadilamouki, A. and Krauthammer, T., “An Explicit Finite-Difference Approach for the Mindlin Plate Analysis”. Computers \& Structures, 1989. 31(4): p. 487-494.

6. Lu, Y. and Gong, S.F., "An analytical model for dynamic response of beam-column frames to impulsive ground excitations". International Journal of Solids and Structures, 2007. 44(3-4): p. 779-798.

7. Krauthammer, T., Assadilamouki, A., and Shanaa, H.M., "Analysis of Impulsively Loaded ReinforcedConcrete Structural Elements .1. Theory”. Computers \& Structures, 1993. 48(5): p. 851-860.

8. Krauthammer, T., Assadilamouki, A., and Shanaa, H.M., "Analysis of Impulsively Loaded ReinforcedConcrete Structural Elements .2. Implementation”. Computers \& Structures, 1993. 48(5): p. 861-871.

9. Shi, Y.C., Hao, H., and Li, Z.X., "Numerical simulation of blast wave interaction with structure columns". Shock Waves, 2007. 17(1-2): p. 113-133. 
10. AUTODYN. Theory manual, Century dynamics, 2006.

11. LS-DYNA. Livermore Software Technology Corporation, Livermore (CA), USA, 2001.

12. Shi, Y.C., Hao, H., and Li, Z.X., "Numerical derivation of pressure-impulse diagrams for prediction of RC column damage to blast loads". International Journal of Impact Engineering, 2008. 35(11): p. 1213-1227.

13. $\mathrm{Xu}, \mathrm{K}$. and Lu, Y., "Numerical simulation study of spallation in reinforced concrete plates subjected to blast loading”. Computers \& Structures, 2006. 84(5-6): p. 431-438.

14. Luccioni, B.M., Ambrosini, R.D., and Danesi, R.F., "Analysis of building collapse under blast loads". Engineering Structures, 2004. 26(1): p. 63-71.

15. Hao, H., Wu C.Q., Li, Z.X., and Abdullah A.K., "Numerical analysis of structural progressive collapse to blast loads". Trans Tianjin Univ, 2006. 12 (Suppl.), p. 31-34.

16. Shi, Y.C., Li, Z.X., and Hao, H., "A new method for progressive collapse analysis of RC frames under blast loading”. Engineering Structures. 32(6): p. 1691-1703.

17. Tang, E.K.C. and Hao, H., "Numerical simulation of a cable-stayed bridge response to blast loads, Part I: Model development and response calculations". Engineering Structures. 32(10): p. 3180-3192.

18. Hao, H. and Tang, E.K.C., "Numerical simulation of a cable-stayed bridge response to blast loads, Part II: Damage prediction and FRP strengthening". Engineering Structures. 32(10): p. 3193-3205.

19. Riedel, W., Mayrhofer, C., Thoma, K. and Stolz A., "Engineering and numerical tools for explosion protection of reinforced concrete", International Journal of Protective Structures, Vol. 1(1), 2010, pp 85-102.

20. Krauthammer, T., "Shallow-Buried RC Box-Type Structures”. Journal of Structural Engineering-Asce, 1984. 110(3): p. 637-651.

21. Krauthammer, T., Shanaa, H.M., and Assadi, A., "Response of Structural Concrete Elements to Severe Impulsive Loads". Computers \& Structures, 1994. 53(1): p. 119-130.

22. Yang, G.C. and Lok, T.S., "Analysis of RC structures subjected to air-blast loading accounting for strain rate effect of steel reinforcement”. International Journal of Impact Engineering, 2007. 34(12): p. 1924-1935.

23. Fitzmaurice, J., Blast Retrofit Design of CMU Walls Using Polymer Sheets. MS Thesis. 2006 - University of Missouri, Columbia, MO.

24. Department of Defense, USA, Structures to Resist the Effects of Accidental Explosions (UFC 3-340-02), Department of Defense, USA, 2008, p. 11-21.

25. Hao H., "A Simple Numerical Approach to Predict Structure Responses to Blast Loading". The First International Conference of protective Structures, Manchester, UK. 2010.

26. Eton, C.E.E.-I.D.B., Ceb-Fip Model Code 1990: Design Code 1993.

27. Malvar, L.J. and Ross, C.A., "Review of strain rate effects for concrete in tension". Aci Materials Journal, 1998. 95(6): p. 735-739.

28. Malvar, L.J., "Review of static and dynamic properties of steel reinforcing bars". Aci Materials Journal, 1998. 95(5): p. 609-616.

29. Biggs, J.M., Introduction to structural dynamics. 1964, New York: McGraw-Hill. 